\title{
The effect of slight thinning of managed coniferous forest on landscape appreciation and psychological restoration
}

\author{
Norimasa Takayama $^{1 *} \mathbb{D}$, Haruo Saito ${ }^{2}$, Akio Fujiwara² and Masahiro Horiuchi ${ }^{3}$
}

\begin{abstract}
We investigated the influence of slight thinning (percentage of woods: $16.6 \%$, basal area: $9.3 \%$ ) on landscape appreciation and the psychological restorative effect of an on-site setting by exposing respondents to an ordinarily managed coniferous woodland. The experiments were conducted in an experimental plot in the same coniferous woodland in May (unthinned) and October 2013 (thinned). The respondents were the same 15 individuals for both experiments. Respondents were individually exposed to the enclosed plot and the forest-view plot within the same tent for $15 \mathrm{~min}$. In both sessions, respondents were required to answer three questionnaires measuring their mood (Profile of Mood States), emotion (Positive and Negative Affect Schedule), and feeling of restoration (Restorative Outcome Scale) to investigate the psychological restorative effect before and after the experiment. They completed two other questionnaires measuring appreciation for the environment (Semantic Differential) and the restorative properties of the environment (Perceived Restorativeness Scale) following the experiments. We first analyzed the difference in landscape appreciation between the unthinned and thinned conditions. We did not find any statistical difference in appreciation for the environment (Semantic Differential) or the restorative properties of the environment (Perceived Restorativeness Scale); rather, we found that weather conditions had a primary influence on landscape appreciation. With respect to the psychological restorative effect, a two-way repeated analysis of valiance (ANOVA) revealed significant main effects for a selection of indices, depending on the presence or absence of thinning. However, multiple comparison analyses revealed that these effects seemed to be due to the difference in the experimental experience rather than the presence or absence of thinning. In conclusion, the effect of the slight thinning of the managed coniferous forest was too weak to be reflected in the respondents' landscape appreciation or to exert a psychological restorative effect. Therefore, planners should consider stronger thinning as it is unlikely to result in serious damage to users' appreciation and may increase their landscape appreciation of coniferous woodland and enhance its psychological restorative effect.
\end{abstract}

Keywords: Forest bathing, Forest management, Profile of Mood States (POMS), Restorative Outcome Scale (ROS), Positive and Negative Affect Schedule (PANAS), Semantic Differential (SD) method, Perceived Restorativeness Scale (PRS)

\section{Introduction}

In Japan, the shortage of timber after the end of World War II prompted the creation of a national policy to plant Japanese cedar (Cryptomeria japonica) and Hinoki cypress (Chamaecyparis obtusa). Currently, forests cover $67 \%$ of the land area and approximately $40 \%$ of these forests are artificial (Food and Agriculture Organization

\footnotetext{
* Correspondence: hanri@ffpri.affrc.go.jp

'Division of Forest Management, Forestry and Forest Products Research Institute in Japan, 1 Matsuno-sato, Tsukuba City, Ibaraki 305-8687, Japan Full list of author information is available at the end of the article
}

2007). However, when domestic timber prices slowed due to the total liberalization of wood imports in 1964, the motivation of private forest owners to manage their forests rapidly diminished.

Forests not only function to provide woodlands but also serve as multifaceted places where biodiversity is preserved, soil outflow is prevented, water sources are recharged, and forest bathing areas are provided. To manage forests that have not been profitable for forestry enterprises, subsidies are used to encourage forest management practices such as tree thinning and weeding to 
enhance their multifunctional functions for the benefit of society. However, scientific evidence is required to prove the effectiveness and validity of such practices due to the use of tax exemptions from inputting subsidies to financial sources (Forestry Agency of Japan 2016).

Japan is a mostly warm and humid country with a suitable climate for growing trees. Thus, to enhance the many functions of artificial forests while responding to future timber demands, it is necessary to artificially thin and prune dense forests. Thinning allows light to filter into the forest, which enhances the growth of the remaining trees and increases the forest's value and biodiversity. This leads to the maximization of the value of the forest, including expectations for additional functions, such as soil support and water source recharging.

Furthermore, thinning maximizes the use of appropriately managed forests as places of recreation and forest bathing, even in artificial forests. Therefore, to maximize the value of forests domestically, national and local governments should require the appropriate thinning of artificial forests by providing subsidies to forestry associations and/or forest owners. However, we should point out that such policies have not been progressing well and have not achieved sufficient outcomes to date (Forestry Agency of Japan 2016).

More than 30 years have passed since Ulrich's (1984) scientific study of the restorative effect of green and nature, during which time the primary focus has been on psychology in relation to city life (Herzog and Chernik 2000; Hartig et al. 2003; Laumann et al. 2003; Morita et al. 2009; Velarde et al. 2007). According to Haluza et al. (2014), since the beginning of this century, the physical and psychological restorative effects or other immunerelated effects of forest enclosures have been investigated primarily in developed countries, in which aging populations and declining birth rates have become serious issues. In Japan in particular, since the concept of forest bathing was defined in 1982 (Morita et al. 2009), studies on the physical and psychological restorative effects of the forest have rapidly advanced, specifically in the second half of the 1990s. For example, in the areas of medicine and physiology, Ohira et al. (1999) reported that forest bathing was effective for immune restoration, and $\mathrm{Li}$ et al. (2007; 2008a) found that immune cells were more active after a 3-day stay in the forest. Li et al. (2008b) also indicated that the benefits of forest bathing were influenced not only by the components of air, such as phytoncide, but also by the environment itself, compared with staying in urban areas for the same duration. Ochiai et al. (2015a; 2015b) showed that $2 \mathrm{~h}$ of forest bathing reduced physiological parameters such as stress hormones, blood pressure, and adrenaline in middle-aged and elderly people. The Profile of Mood States (POMS; McNair et al. 1964) and the StateTrait Anxiety Inventory (STAI; Spielberger et al. 1970; Spielberger et al. 1983) are commonly applied to analyze mood (Oishi et al. 2003; Park et al. 2009; Tsunetsugu et al. 2010; Park et al. 2010) and anxiety state (Takanashi 2011). Moreover, research using newly developed indices such as the Perceived Restorativeness Scale (PRS; Korpela and Hartig 1996; Hartig et al. 1997a; Hartig et al. 1997b), the Restorative Outcome Scale (ROS; Korpela et al. 2008; Korpela et al. 2010), and the Subjective Vitality Scale (SVS; Ryan and Frederick 1997) has shown that forest bathing results in psychological restoration and improved vigor (Takayama and Kagawa 2013; Takayama, Korpela, Lee et al. 2014b; Tyrväinen et al. 2014). Furthermore, Kobayashi et al. (2015) performed a large-scale field experiment throughout Japan in 60 forests known as "therapy bases" maintained for forest bathing. Finally, a few notable studies have confirmed the considerable physiological and psychological effects not only of remote forests but also of urban forests (Tsunetsugu et al. 2013; Tyrväinen et al. 2014b). Thus, studies have shown that forest environments result in physical and mental restorative effects and have detailed the mechanisms behind these effects.

However, forest management planning is required to activate the health-restorative function of a forest. Information on the arrangement of physical forest environments and their management is needed to make forests a comfortable place to be. In the context of the effects of the physical forest environment and forest bathing, Horiuchi et al. (2014) reported that when individuals observed a real forest scene, the level of cerebral oxygenated hemoglobin in the prefrontal area of the brain declined and mood improvements were greater than in respondents who were cut off from forest environments. Park et al. (2011) demonstrated a relationship between physical conditions, such as temperature and illumination, and impression evaluation and mood restoration. Fujisawa et al. (2012) and Takayama et al. (2012) studied the light environment in forests and reported that in a bright environment with sunlight passing through the trees, the blood volume in the brain decreased and mood improvement effects were higher than in a dark environment within the same forest. These research findings suggest that it is important to properly manage the forest's internal environment to make forest bathing more comfortable. However, forest management requires an understanding of the unique situation within each forest depending on its intended use (Brunson and Reiter 1996; Gobster 1999; Ribe 2006). For example, compared with remote artificial forests, forests near tourist spots or suburban forests require management to maintain biological diversity while at the same time satisfying the needs of tourists and residents of nearby neighborhoods (Brunson and Reiter 1996; Gobster 1999; Ribe 2006). Therefore, to manage urban forests with highly diverse uses such as forest bathing and other recreational activities, an administrator must be well informed about the level of management required in relation to intended uses. 
Other studies have assessed the relationship between forest management methods and public evaluation. For instance, Buhyoff and Leuschner (1978) reported that favorability ratings for forests decreased sharply after the pinewood nematode caused damage to more than 10\%; Takahashi et al. (2006) suggested that preferences vary depending on the mix of tree types and the proportion of hardwood and softwood; and Oishi et al. (1994), Takayama et al. (2009), and Takayama et al. (2014) investigated the relationship between tree density and the comfortability of the forest environment. Several investigators have studied the effects of the types and numbers of trees, tree density, the presence or absence of fallen trees, and planting patterns on the evaluation of landscape beauty, among other parameters.

The relationship between the evaluation of forest beauty and thinning, which is a typical method of sustaining forests, has also been investigated (Ribe 2005; Guan et al. 2010; Deng et al. 2012). Daniel (2006) highlighted that forest users tend to prefer somewhat managed forests to entirely natural forests. However, Edwards et al. (2012) showed that thinning was not the only task necessary to preserve forests in good condition. Even if thinning improves the internal forest environment, the evaluation of the forest has been shown to decrease after thinning. Nevertheless, further studies are necessary to collect data on the extent of users' impact and the reduction in esthetic evaluation by controlling the forest type, stand age, forest compartment placement, and the degree of thinning.

Other studies have investigated the relationship between forest landscape management and recreation. Brunson and Sheldy (1992) found that the landscape quality of a forest and recreational activities were closely linked. Kunisaki and Imada (1996) reported that managing the density of trees along roads such as promenades, forest trails, and forest roads increased users' satisfaction, even if sufficient thinning could not be conducted for the entire forest. The Gifu Prefectural Research Institute for Forests (2004) reported that good visitor ratings could be maintained by establishing a range of approximately $20 \mathrm{~m}$ from both sides of the sidewalk. Lastly, Oku (2007) investigated the ease of carrying out various activities in the forest, which included an analysis of the level of management required for each type of use.

Another important aspect is how users' evaluations of forests change depending on the degree of thinning and its relationship to mental and physical recovery. Unfortunately, only a few previous studies have considered this topic, such as Oishi et al. (2003), and current research remains insufficient for specialists to form actionable conclusions. Urban forests located close to cities, or in resort or vacation areas that have already been in service for tourism or other recreational uses, offer facilities that are reasonably maintained and managed, unlike distant forests (e.g., okuyama; forests and mountains far from urban areas) that are in a state of abandonment. However, health consciousness has recently emerged as a public issue, and forest managers must further enhance their general evaluation of forests to continually provide forest bathing experiences that bring a restorative effect to visitors. Therefore, management criteria are required that provide guidelines on the optimal amount and frequency of thinning, weeding, and pruning to establish appropriate goals and guide forest management. With insufficient evidence, forest administrators must decide arbitrarily on the need for and degree of thinning using their own judgment, experience, demand, and other plans (for example, timber production planning), without measurable objectives. If we cannot promote the benefits of thinning due to a lack of information on forest management and the mental and physical restorative effects of forest environments, both forest administrators and users may miss a great opportunity.

In this study, we performed an experiment in which adjusted thinning was carried out in a partially managed urban forest located in a suburban summer resort. The purpose of the study was to investigate how thinning influenced impressions and evaluations of the forest environment and its restorative effects on people who enjoy forest bathing.

\section{Methods/experimental \\ Study design}

The experiment was divided into two parts and conducted in May and October, when the average temperature and humidity were expected to be similar (see the "Results and discussion" section). The study area chosen was within the Fuji Iyashinomori Woodland Study Center, which is an experimental forest associated with the University of Tokyo located in Yamanakako Village. This institute is located near Lake Yamanaka, one of the five lakes around Mt. Fuji (Fig. 1), and the experimental plot measured $2500 \mathrm{~m}^{2}(50 \mathrm{~m} \times 50 \mathrm{~m}$; Fig. 2, Table 1$)$.

The forest chosen as the research site (approximately $40 \mathrm{ha}$ ) is managed by two technical staff members of the Fuji Iyashinomori Woodland Study Center. The university budget covers the management expenses of the forest. The area around the Center, the buildings, gardens, forest road, and sidewalks are highly managed. However, the management status of the Larch plantation area chosen as the research site was similar to other surrounding private forests and was not highly managed, at least at the time of the experiment. The forest physiognomy (forest type) of the experimental plot was a man-made (artificial) forest primarily comprising approximately 80-year-old larch trees (Larix kaempferi); however, the amount of hardwood trees was increasing, and the forest was turning into a mixed-type forest. In 2012, 1 year before the experiment, the shrubs and young trees were cut and removed from the forest. Therefore, the canopy was almost closed, but the horizontal prospect was in quite good condition (Figs. 3 and 4 and Table 2). 


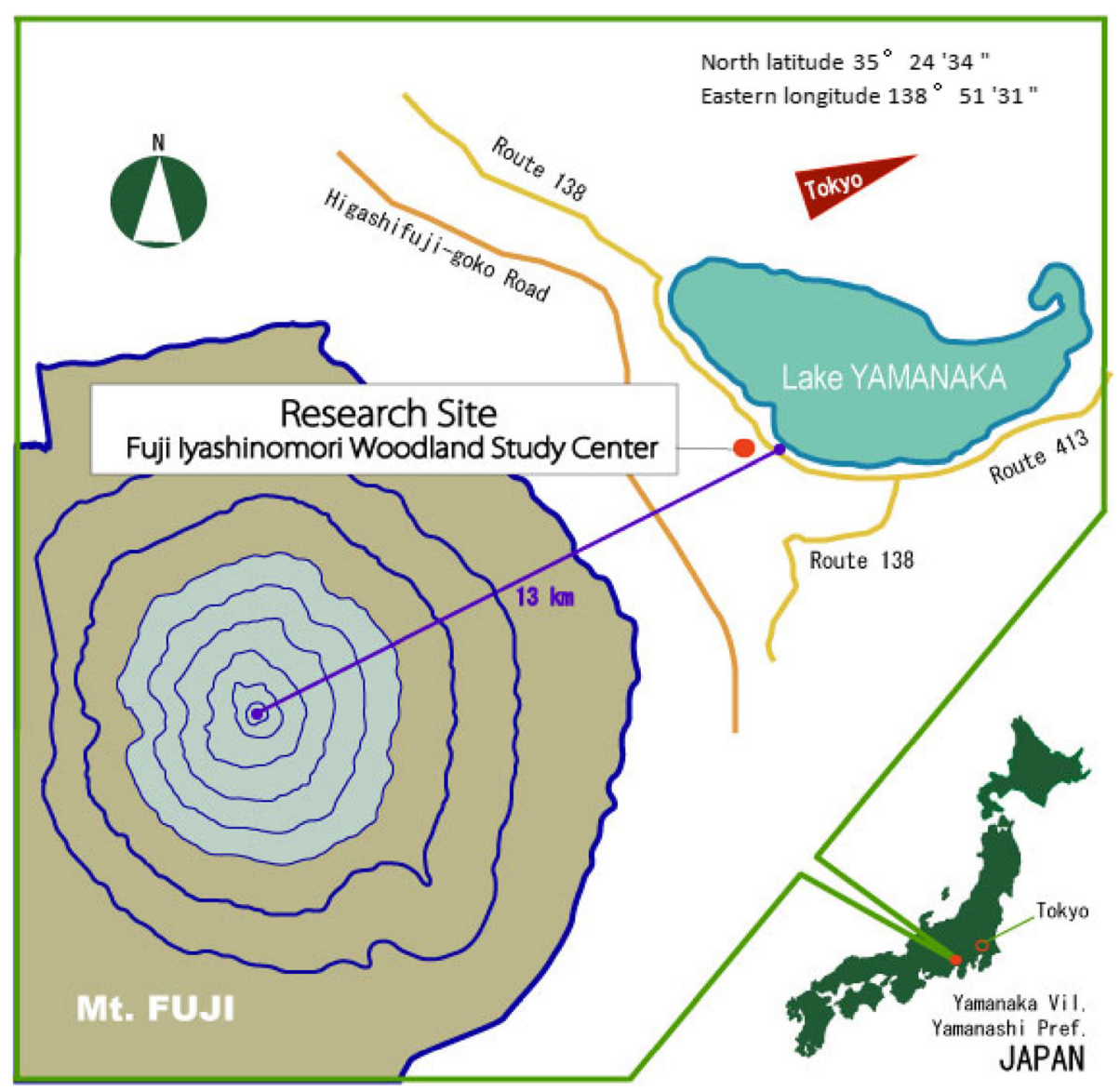

Fig. 1 Location of the research site

Following the completion of the first experiment in May 2013, corrective thinning of the study area was carried out in August of the same year. Crews used two chain saws and one portable winch during the thinning operation, with a target of approximately $15-20 \%$ thinning. Four workers from Fuji Iyashinomori Woodland Study Center worked for a total of $9 \mathrm{~h}$ for 2 days in late August. The second experiment was conducted in October of the same year. The period between the two experiments was important because the smell of the trees, typified by phytoncide, would be stronger immediately after the thinning. In the experimental period, we provided warm coats for the participants so they could control the experimental conditions in comfort. Table 2 shows the distribution of vegetation used for the experimental stimuli, based on the basal area at breast height in May (in October).

\section{Respondents}

Graduate students and teaching staff members from the Forest Science Department of the University of Tokyo were chosen as the respondents in this experiment. Therefore, we could assume that all respondents were favorable toward and had fundamental knowledge and experience of forests. We broadened the sample to include middle-aged teaching staff to avoid the bias that may have occurred by choosing only students. Fifteen respondents (11 men and 4 women) with a mean age of $35.9 \pm 8.19$ years (Table 3 ) participated in this study. The respondents had no history of cardiovascular disease or mental illness and were not taking any medications that could affect their psychological responses related to feelings, affect, and subjective restorativeness. Following a detailed description and explanation of the study procedures and the possible risks and benefits of participation, each respondent signed an informed consent form. Respondents were randomly divided into group A or group B and asked to abstain from consuming caffeinated beverages for $12 \mathrm{~h}$ and not to engage in strenuous exercise or consume alcohol for a minimum of $24 \mathrm{~h}$ before the experiment. The ethical committee of the Mt. Fuji Research Institute approved all procedures applied in the present study, which were performed in accordance with the guidelines of the Declaration of Helsinki.

We performed a statistical power analysis using the free software G*power v. 3.1.9.2. The actual power (1- $\beta$ error probability) was 0.575 for a repeated measures, withinbetween interaction test, calculated by a post hoc achieved 


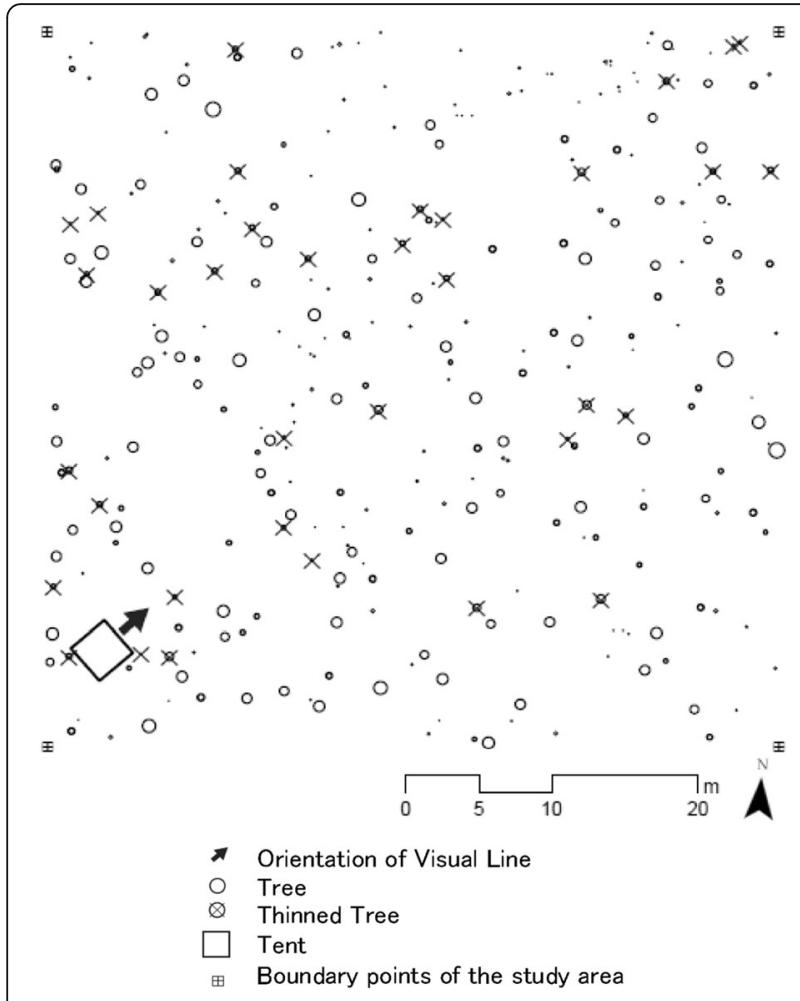

Fig. 2 Situation of the experimental area

power analysis with an effect size of 0.25 and $\alpha$ error of probability of 0.05 . Nevertheless, previous studies have indicated that a sample size of $12-15$ respondents is enough to draw significance conclusions (Li et al. 2008a; Li et al. 2008b; Park et al. 2009; Horiuchi et al. 2014).

\section{Questionnaires}

The study used five psychological questionnaires. Figure 5 shows the administration procedure for each questionnaire. The purpose was to evaluate the characteristics of

Table 1 Research site characteristics and weather conditions

\begin{tabular}{lll}
\hline & May & October \\
\hline Location & $\begin{array}{l}\text { Fuji lyashinomori Woodland Study Center, } \\
\text { Yamanaka Lake Town, Yamanashi Prefecture }\end{array}$ \\
Experimental area & $2500 \mathrm{~m}^{2}(50 \mathrm{~m} \times 50 \mathrm{~m})$ \\
Forest status & Well-managed mixed forest \\
& $(80$-year-old Larch and Dogwood) \\
Weather & & \\
Day1 & Fair & Cloudy \\
Day2 & Fair & Cloudy and/or partly sunny \\
Day3 & Fair & Cloudy and/or partly sunny \\
Day4 & Fair & Cloudy and/or partly rainy \\
Monthly mean temp. $\left({ }^{\circ} \mathrm{C}\right)$ & 12.8 & 10.9 \\
Monthly mean humidity (\%) & 84.6 & 90.9 \\
\hline
\end{tabular}

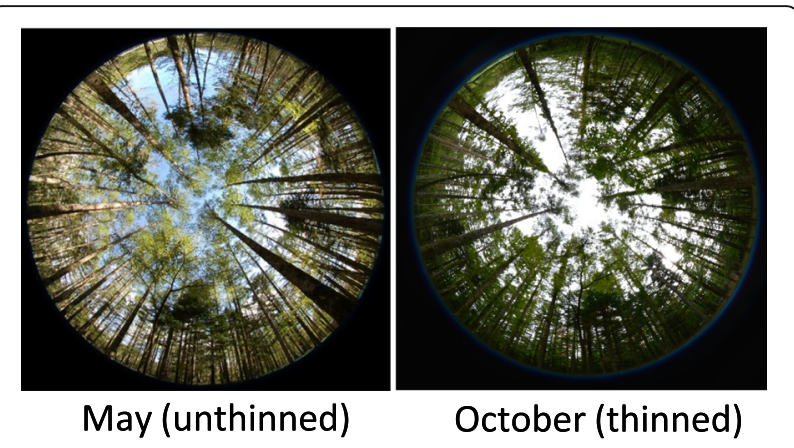

Fig. 3 Hemispherical photographs of the study area

the forest environment and to investigate its psychological restorative effect. Because the psychological evaluations were in the form of language information, generally it would be easy to interpret them in comparison with physiological data to facilitate future forest management. Therefore, we decided to use five psychological questionnaires in the experiment. Specifically, the POMS, ROS, and PANAS measured the psychological restorative effect, and the SD method and PRS measured the characteristics of the forest environment.

\section{1) Profile of Mood States (POMS)}

The POMS (McNair et al. 1964) is a well-established, factor-based, analytically derived measure of psychological distress. Its reliability and validity have been well documented (McNair et al. 1964). The POMS measures six mood states: tension and anxiety (T-A), depression-dejection (D), anger and hostility $(\mathrm{A}-\mathrm{H})$, vigor $(\mathrm{V})$, fatigue $(\mathrm{F})$, and confusion $(\mathrm{C})$. We used the Brief Form Japanese Version of the POMS (Yokoyama et al. 1990). Each subscale has five items measured on a 5-point Likert scale; thus, the statistical analyses included the raw scores for all 30 items.

2) Positive and Negative Affect Schedule (PANAS) The PANAS (Watson et al. 1988a; Watson et al. 1988b) measures positive affect (PA) and negative affect (NA) using 20 items (10 items each for PA and NA). The scales have high internal consistency, are largely uncorrelated, and remain stable at appropriate levels over a 2-month period (Watson et al. 1988b). Normative data, factorial elements, and external evidence of the scales' convergent and discriminant validity are also available (Watson et al. 1988b). We used the Japanese version of the PANAS (16 items; 8 items each for PA and NA; measured on a 7-point Likert scale; Sato and Yasuda 2001) and used each respondent's total PA and NA scores in the statistical analyses.

3) Restorative Outcome Scale (ROS)

The ROS (Korpela et al. 2008) was based on previous measures and findings regarding restorative 


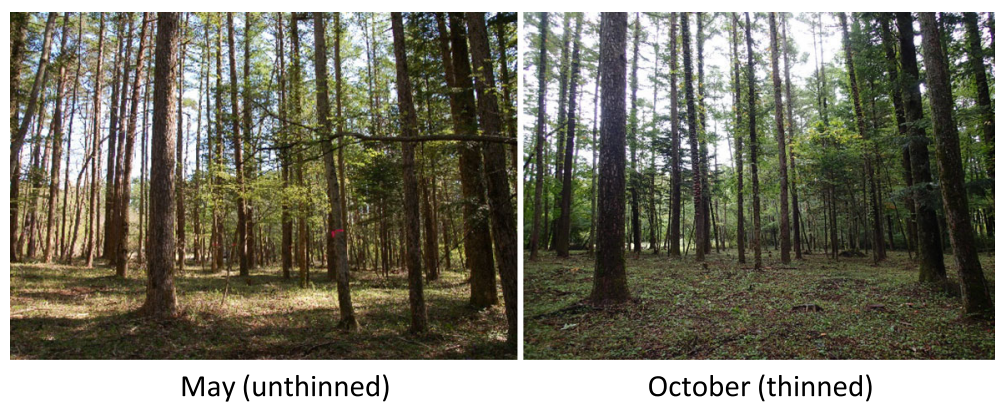

Fig. 4 View of the study area

outcomes (Kaplan et al. 1993; Hartig et al. 1998; Staats et al. 2003). The ROS consists of six items for measuring restorative emotional and cognitive outcomes in a given environment. Each item is measured on a 7-point Likert scale (1: "not at all" to 7: "completely"), the reliability of which was confirmed in previous studies (Korpela et al. 2008; Korpela et al. 2010). In this study, we used the Japanese version, the ROS-J, and checked the reliability and validity according to Fujisawa and Takayama (2014). The total score of the six items was used for statistical analyses.

4) Semantic Differential (SD) method A questionnaire using the SD method was applied to examine the impression of the different environments. Osgood (cited in Iwashita 1983)

Table 2 Species data for May and October

\begin{tabular}{llll}
\hline & & $\begin{array}{l}\text { May } \\
\text { (unthinned) }\end{array}$ & $\begin{array}{l}\text { October } \\
\text { (thinned) }\end{array}$ \\
\hline $\begin{array}{l}\text { Stand density } \\
\text { (number/ha) }\end{array}$ & $\begin{array}{l}1200 / \mathrm{ha} \\
(n=301)\end{array}$ & $\begin{array}{l}1056 / \mathrm{ha} \\
(n=251)\end{array}$ \\
$\begin{array}{l}\text { Stand basal area } \\
\text { (m²/ha) }\end{array}$ & 48.8 & 44.3 \\
$\begin{array}{l}\text { Species composition } \\
\text { (basal area; \%) }\end{array}$ & $\begin{array}{l}\text { Larch } \\
\text { (Larix kaempferi) }\end{array}$ & $66.2 \%$ & $66.1 \%$ \\
& $\begin{array}{l}\text { Dogwood } \\
\text { (Cornus kousa) }\end{array}$ & $10.1 \%$ & $10.1 \%$ \\
& $\begin{array}{l}\text { Red pine } \\
\text { (Pinus densiflora) }\end{array}$ & $7.0 \%$ & $7.3 \%$ \\
& $\begin{array}{l}\text { Fir (Abies firma) } \\
\text { Japanese-alder }\end{array}$ & $6.4 \%$ & $6.4 \%$ \\
& $\begin{array}{l}\text { (Alnus japonica) } \\
\text { Veitch's silver fir }\end{array}$ & $1.9 \%$ & $1.8 \%$ \\
& $\begin{array}{l}\text { (Abies veitchii) } \\
\text { Fuji cherry } \\
\text { (Prunus incisa) }\end{array}$ & $0.8 \%$ & $1.8 \%$ \\
& $\begin{array}{l}\text { Maple (Acer) } \\
\text { Japanese wing nut } \\
\text { (Pterocarya rhoifolia) } \\
\text { Others }\end{array}$ & $0.7 \%$ & $0.8 \%$ \\
\hline
\end{tabular}

initially developed the SD method for qualitatively evaluating people's impressions of the environment and space, using adjective pairs or adjective-verb pairs of words with opposite meanings. Park et al. (2011) and Takayama et al. (2014) proved the effectiveness of this scale in previous studies; therefore, in this study, we selected 25 adjective and adjective-verb pairs that were considered appropriate for evaluating impressions of the forest environment. A 7-point Likert scale was used for the measurement.

5) Perceived Restorativeness Scale (PRS)

The restorative properties of the environment were investigated using the PRS. The questionnaire was developed by Harting (2005) based on the attention restoration theory proposed by Kaplan and Kaplan (1989) and Shibata et al. (2008), then translated into Japanese and subsequently revised. The Japanese version of the PRS comprises 26 items that measure the extent to which a particular environment restores mental alertness; for example, "being away," "fascination," "coherence," "scope," and "compatibility" on an 11-point Likert scale. "Familiarity" and "preference" were also measured (Kaplan and Kaplan 1989; Shibata et al. 2008).

\section{Procedure}

All respondents were divided into either group A or group $\mathrm{B}$ in May and remained in the same groups for the October experiment. There were two study conditions, and each respondent participated in both in a certain order in May and October (Fig. 5). One condition included viewing a real forest, whereas the other was in the same place but respondents did not view the real forest. Cloth sheets were

Table 3 Respondents' characteristics

\begin{tabular}{llll}
\hline & Number of respondent & Mean age & S.D. \\
\hline All & 15 & 35.9 & \pm 8.19 \\
Male & 11 & 37.4 & \pm 7.58 \\
Female & 4 & 31.8 & \pm 9.53 \\
\hline
\end{tabular}




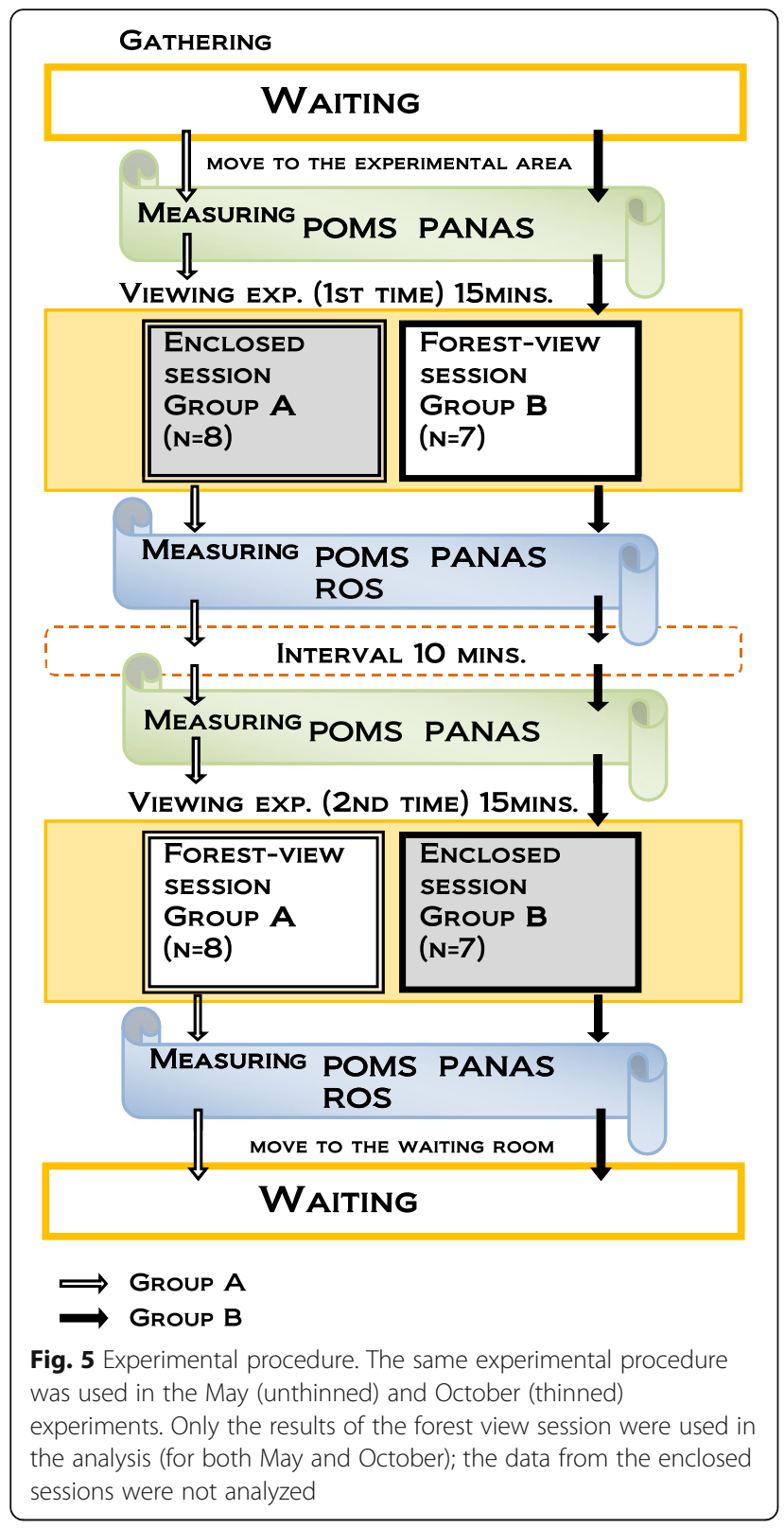

hung on both sides and in front of the respondent for the entire duration of the study. The cloth in front of the respondent was opened and closed for the forest-view and enclosed conditions (with and without forest viewing, respectively) in both May and October.

Respondents' psychological responses were measured in both the forest-view and enclosed conditions. Each respondent sat on a comfortable chair during both conditions. The POMS, PANAS, and ROS were administered before and after, and the SD and PRS were administered after each 15-min experimental session. Respondents sat in a comfortable chair in an upright position to complete the POMS, ROS, and PANAS questionnaires. Respondents were then instructed to view the landscape in front of them, either the forest or the enclosed setting, for $15 \mathrm{~min}$. The post-measurements were then completed (i.e., POMS, ROS, PANAS, SD, and PRS). After completing either the forest-view or enclosed condition, the other experimental stimulus was introduced.

Carrying out the experiment according to the schedule shown in Fig. 5 required approximately 2 h per respondent, and only three or four people could be tested each day because of the individual experimental design. Therefore, the 15 respondents were tested over four consecutive days in each of May and October.

\section{Environmental measurements}

Environmental conditions (i.e., temperature and relative humidity, wind velocity, and radiant heat) were measured using a portable amenity meter (AM-101, Kyoto Electronic Manufacturing, Co. Ltd, Kyoto, Japan). Illumination intensity was measured using an illuminometer ( $\mathrm{T}-10$, Konica Minorta, Japan). These parameters were measured every $5 \mathrm{~min}$ throughout the $15 \mathrm{~min}$ of each experimental session.

\section{Data analysis}

We aggregated the study index data and calculated the mean and standard deviation (SD). Only the results of the forest-view sessions were used for the analysis in both May and October. We conducted a two-way repeated measure analysis of valiance (ANOVA) on the POMS, PANAS, and ROS data to investigate the psychological restorative effect of forest thinning. The interaction and simple main effects were calculated to investigate the relationship between the response changes of the exposure to the stimulus (before and after exposure) and the thinning (May-October). The SD method and PRS, which were used as indicators of landscape appreciation, were only administered after exposure to the stimulus. Therefore, we compared the results of the May and October experiments using paired $t$-tests to investigate whether the evaluations changed after the forest thinning. We calculated the average values of the environmental condition indicators over the $15 \mathrm{~min}$ of each experimental session, and compared the values of each indicator between May and October using paired $t$-tests. Data are expressed as mean \pm SD.

\section{Results and discussion \\ Physical environment}

Table 4 shows the results of the physical environment measurements for the unthinned and thinned conditions. First, in the thinned experimental environment in October, the temperature and humidity were significantly higher $(p<0.01)$ than in the unthinned environment in May, the wind was calmer $(p<0.05)$ and the radiant heat was lower $(p<0.05)$. Illuminance was significantly lower in the thinned condition $(p<0.01)$ than in the unthinned condition. The sound 
Table 4 Results of $t$-test comparison between the unthinned and thinned settings (physical environment)

\begin{tabular}{|c|c|c|c|c|c|c|c|c|c|}
\hline Item & & Unthinned & & Thinned & & $t$ & $p$ & & $r$ \\
\hline & & Mean & S.D. & Mean & S.D. & & & & \\
\hline Temperature $\left({ }^{\circ} \mathrm{C}\right)$ & $n=50$ & 17.1 & \pm 2.52 & 18.6 & \pm 0.92 & 2.90 & 0.006 & ** & 0.383 \\
\hline Relative humidity (\%) & & 37.7 & \pm 20.42 & 92.4 & \pm 4.64 & 13.70 & 0.000 & $* *$ & 0.891 \\
\hline Wind velocity $(\mathrm{m} / \mathrm{s})$ & & 0.30 & \pm 0.19 & 0.16 & \pm 0.13 & 4.92 & 0.000 & $*$ & 0.576 \\
\hline Radiant heat $\left({ }^{\circ} \mathrm{C}\right)$ & & 21.8 & \pm 2.84 & 18.8 & \pm 1.05 & 2.19 & 0.034 & ** & 0.299 \\
\hline Illuminance (Lux) & $n=119$ & 668.4 & \pm 236.86 & 335.6 & \pm 171.84 & 8.23 & 0.000 & $* *$ & 0.604 \\
\hline Sound pressure $(\mathrm{dB})$ & & L.O. up to 45.5 & & L.O. up to 46.1 & & - & - & - & - \\
\hline
\end{tabular}

L.O. shows the measurement limit (less than $40 \mathrm{~dB}$ ) of the sound-level meter. The $\mathrm{dB}$ was listed from the minimum (measurement limit) to the maximum (actual number) as information of the sound pressure

${ }^{* *} p<0.01,{ }^{*} p<0.05$, paired $t$-test

pressure level for the thinned and unthinned conditions was similar, considering $45-46 \mathrm{~dB}$ as the measurement limit.

To carry out the on-site comparative experiments, the state of the forest environment should be equal in the unthinned and thinned conditions. Therefore, we chose to carry out the experiments in May and October, which generally have similar weather conditions. However, as shown in Table 4, we observed significant differences in the thermal environment and illumination. More specifically, the results show that in the thinned forest environment in October, the luminance was slightly lower and the temperature was higher than in the unthinned environment in May.

\section{Landscape appreciation}

Table 5 compares the evaluations of the unthinned and thinned forest environments. We observed a significant difference in the two measures (scales) of "bright-dark" $(p<0.05)$ and "dry-wet" $(p<0.01)$. In other words, the thinned forest environment was evaluated to be relatively dark and wet. We also observed different trends $(p<0.1)$ in three scales: "gentle lighting-too bright," "dull-refreshing," and "thin-thick." Respondents used the labels "gentle light," but not "refreshing" or "thin" to describe the thinned forest environment.

Table 6 compares the restorative properties of the two forest environments based on the appreciation of the respondents. The results show no significant difference between the indicators used to measure the restorative properties (being away, fascination, coherence, scope, and compatibility) and familiarity and preference.

These results indicate that although the thinning operation physically changed the stand density and basal area of the forest environment (Fig. 2, Table 2), the impression evaluation and restorative properties indicators showed almost no difference between the forest environments (Tables 5 and 6). The SDs suggested that the thinned forest environment was evaluated as darker and wetter. However, this result was not because of the influence of the thinning, but rather reflected the difference in the climate and weather conditions during the experiment; for example, the luminance was lower and the humidity was higher (Table 4).

Table 4 also indicates that respondents felt the thinned condition was relatively "dull" (dull-refreshing) and the light in the forest "gentle" (gentle lighting-too bright), which implies that the climate and weather conditions in the thinned condition, when the humidity was higher and the luminance was lower, had an influence.

\section{Psychological restorative effect}

Because both the thinning and the exposure to the forest environment could influence the psychological restorative effect, we conducted a two-way repeated measures ANOVA, with the presence or absence of thinning and the observations before and after exposure to the forest environment as factors, to analyze the interaction between the factors and the main effect (Tables 7 and 8). The results showed no interaction effect between the presence and absence of thinning and before and after the experiment for the six indicators of the POMS (T-A, D, A-H, V, F, C).

We also examined each main effect of the presence or absence of thinning and the observations before and after the experiment. For the former, we observed a significant effect in $\mathrm{C}(p<0.01)$ and a trend in T-A $(p<$ $0.1)$. For the latter, we observed a significant effect in $\mathrm{T}$ $\mathrm{A}$, D, and $\mathrm{C}(p<0.01$, respectively), and a trend in $\mathrm{F}(p<$ 0.05) (Table 7).

Based on the results of the multiple comparison tests, the numeric values of T-A, D, F, and C showed a significant reduction and the respondents' mood was improved $(p<0.01)$ in the unthinned condition. In the thinned condition, the numeric values of T-A, D, C, and A-H decreased significantly $(p<0.05)$, and $\mathrm{F}$ also showed a declining trend $(p<0.1)$ (Table 8$)$.

The psychological restorative effect was assessed by performing a two-way repeated measures ANOVA on the PANAS data, considering the presence or absence of thinning (unthinned-thinned) and the observations before 
Table 5 Results of t-test comparison between unthinned and thinned settings (Semantic Differential Method)

\begin{tabular}{|c|c|c|c|c|c|c|c|c|}
\hline & \multicolumn{2}{|c|}{ Unthinned } & \multicolumn{2}{|c|}{ Thinned } & \multirow[t]{2}{*}{$t$} & \multirow[t]{2}{*}{$p$} & & \multirow[t]{2}{*}{$r$} \\
\hline & mean & S.D. & mean & S.D. & & & & \\
\hline Bright (1) - Dark (7) & 2.3 & \pm 0.8 & 3.1 & \pm 1.19 & -2.48 & 0.027 & * & 0.552 \\
\hline Open (1) - Closed (7) & 2.3 & \pm 1.11 & 2.7 & \pm 1.35 & -1.03 & 0.320 & & 0.266 \\
\hline Artificial (1) - Natural (7) & 5.7 & \pm 0.82 & 5.4 & \pm 1.3 & 0.59 & 0.565 & & 0.156 \\
\hline Smelly (1) - Odorless (7) & 3.6 & \pm 1.35 & 3.3 & \pm 1.23 & 0.48 & 0.639 & & 0.128 \\
\hline Still (1) - Animated (7) & 5.0 & \pm 1 & 4.5 & \pm 1.13 & 1.37 & 0.192 & & 0.345 \\
\hline Comfortable (1) - Uncomfortable (7) & 2.5 & \pm 1.06 & 2.7 & \pm 1.22 & -0.49 & 0.629 & & 0.131 \\
\hline Quiet (1) - Noisy (7) & 3.2 & \pm 1.35 & 3.3 & \pm 1.5 & -0.24 & 0.815 & & 0.064 \\
\hline Ugly (1) - Beautiful (7) & 5.6 & \pm 0.74 & 5.3 & \pm 0.9 & 1.07 & 0.301 & & 0.277 \\
\hline Pleasing sound (1) - Irritating noise (7) & 2.5 & \pm 1.41 & 3.1 & \pm 1.25 & -1.21 & 0.245 & & 0.309 \\
\hline Friendly (1) - Unfriendly (7) & 2.4 & \pm 0.74 & 2.3 & \pm 0.72 & 0.32 & 0.751 & & 0.087 \\
\hline Dull (1) - Refreshing (7) & 5.9 & \pm 0.64 & 5.1 & \pm 1.44 & 1.87 & 0.082 & $\#$ & 0.448 \\
\hline Orderly (1) - Chaotic (7) & 3.7 & \pm 1.39 & 3.7 & \pm 1.18 & 0.12 & 0.906 & & 0.033 \\
\hline Warm (1) - Cool (7) & 4.9 & \pm 1.03 & 4.7 & \pm 1.23 & 0.72 & 0.484 & & 0.189 \\
\hline Insecure (1) - Secure (7) & 4.9 & \pm 1.1 & 4.6 & \pm 1.18 & 0.66 & 0.519 & & 0.174 \\
\hline Gentle lighting (1) - Too bright (7) & 2.8 & \pm 0.94 & 2.3 & \pm 0.7 & 1.88 & 0.081 & \# & 0.449 \\
\hline Thin (1) - Thick (7) & 4.0 & \pm 0.66 & 3.3 & \pm 0.98 & 1.78 & 0.096 & \# & 0.431 \\
\hline Flat (1) - Three dimensional (7) & 5.3 & \pm 1.5 & 5.3 & \pm 1.35 & 0.00 & 1.000 & & 0.000 \\
\hline Awaking (1) - Soothing (7) & 4.7 & \pm 1.16 & 4.9 & \pm 1.44 & -0.39 & 0.700 & & 0.105 \\
\hline Enchanted (1) - Disenchanted (7) & 3.5 & \pm 0.74 & 3.2 & \pm 1.08 & 0.79 & 0.442 & & 0.207 \\
\hline Fragrant (1) - Malodorous (7) & 3.5 & \pm 0.74 & 3.3 & \pm 0.7 & 0.94 & 0.364 & & 0.244 \\
\hline Non enjoyable (1) - Enjoyable (7) & 5.7 & \pm 0.59 & 5.8 & \pm 0.78 & -0.27 & 0.792 & & 0.072 \\
\hline Restless (1) - Calm (7) & 5.4 & \pm 1.18 & 5.3 & \pm 1.44 & 0.26 & 0.796 & & 0.071 \\
\hline Dry (1) - Wet (7) & 3.8 & \pm 0.86 & 5.3 & \pm 0.96 & -3.90 & 0.002 & ** & 0.722 \\
\hline Nondescript (1) - Unique (7) & 3.4 & \pm 0.74 & 3.7 & \pm 1.03 & -1.05 & 0.313 & & 0.27 \\
\hline Healthy (1) - Unhealthy (7) & 2.5 & \pm 0.52 & 2.4 & \pm 0.83 & 0.62 & 0.546 & & 0.164 \\
\hline
\end{tabular}

Likert scale of seven stages was used for this questionnaire

${ }^{* *} p<0.01,{ }^{*} p<0.05,{ }^{\#} p<0.1$ paired $t$-test

and after the experiment (pre-post) as factors, similar to the POMS (Tables 9 and 10).

We did not observe any interaction between the presence and absence of thinning and pre-post observations on the two PANAS indices (negative and positive).

Table 6 Results of $t$-test comparison between unthinned and thinned settings (Perceived Restorativeness Scale)

\begin{tabular}{|c|c|c|c|c|c|c|c|}
\hline & Unthinned & & Thinned & & $t$ & $p$ & $r$ \\
\hline & Mean & S.D. & Mean & S.D. & & & \\
\hline Being away & 34.2 & \pm 5.98 & 33.9 & \pm 8.54 & 0.11 & 0.912 & 0.031 \\
\hline Fascination & 35.1 & \pm 6.3 & 33.1 & \pm 8.32 & 0.72 & 0.481 & 0.191 \\
\hline Coherence & 20.3 & \pm 4.27 & 21.3 & \pm 5.62 & -0.45 & 0.657 & 0.121 \\
\hline Scope & 22.7 & \pm 5.85 & 26.5 & \pm 5.88 & -1.62 & 0.128 & 0.397 \\
\hline Compatibility & 27.5 & \pm 4.19 & 28.9 & \pm 2.67 & -0.84 & 0.413 & 0.221 \\
\hline Familiality & 5.2 & \pm 2.83 & 6.0 & \pm 2.83 & -0.86 & 0.403 & 0.225 \\
\hline Preference & 11.7 & \pm 2.23 & 11.7 & \pm 3.37 & -0.06 & 0.954 & 0.016 \\
\hline
\end{tabular}

paired $t$-test
Additionally, no significant effect was found for the main effects (Table 9). The results of the multiple comparison tests showed no significant difference between the respondents' negative and positive emotions before and after the experiment in both the unthinned and thinned conditions (Table 10). To assess the psychological restorative effect, we carried out a two-way repeated measures ANOVA on the ROS data with the presence and absence of thinning and pre-post measures as factors, similar to the POMS and PANAS analyses (Tables 11 and 12).

We did not find an interaction between the presence of thinning and the pre-post measures. For the main effects, we observed a significant effect before and after the experiment $(p<0.05)$, but not between the presence and absence of thinning (Table 11). In the unthinned condition, there was a significant difference between pre and post ROS scores $(p<0.01)$. However, although the post scores also increased in the thinned condition, the difference was not significant (Table 12). 
Table 7 Results of two-way repeated measures ANOVA for Profile of Mood States (mood)

\begin{tabular}{|c|c|c|c|c|c|c|c|c|c|c|c|}
\hline \multirow[t]{3}{*}{ POMS } & \multicolumn{8}{|c|}{ Main effect } & \multirow{2}{*}{\multicolumn{3}{|c|}{$\frac{\text { Interaction }}{\text { Condition } \times \text { time }}$}} \\
\hline & \multicolumn{4}{|c|}{$\begin{array}{l}\text { Condition } \\
\text { Unthinned vs. thinned }\end{array}$} & \multicolumn{4}{|c|}{$\begin{array}{l}\text { Time } \\
\text { Pre vs. post }\end{array}$} & & & \\
\hline & F & $p$ & & $\eta^{2}$ & $F$ & $p$ & & $\eta^{2}$ & $F$ & $p$ & $\eta^{2}$ \\
\hline Tension-Anxiety & 3.51 & 0.072 & \# & 0.032 & 5.02 & 0.033 & * & 0.110 & 0.06 & 0.805 & 0.001 \\
\hline Depression-Dejection & 0.20 & 0.662 & & 0.002 & 4.41 & 0.045 & $*$ & 0.115 & 1.06 & 0.312 & 0.006 \\
\hline Anger-Hostility & 2.03 & 0.165 & & 0.018 & 1.76 & 0.195 & & 0.044 & 1.04 & 0.318 & 0.009 \\
\hline Vigor & 1.88 & 0.182 & & 0.021 & 1.35 & 0.256 & & 0.031 & 0.01 & 0.923 & 0.001 \\
\hline Fatigue & 2.15 & 0.153 & & 0.013 & 4.12 & 0.052 & $\#$ & 0.105 & 1.16 & 0.291 & 0.007 \\
\hline Confusion & 35.35 & 0.000 & $* *$ & 0.189 & 4.57 & 0.041 & * & 0.093 & 0.20 & 0.661 & 0.002 \\
\hline
\end{tabular}

${ }^{* *} p<0.01,{ }^{*} p<0.05,{ }^{*} p<0.1$ two-way repeated measures ANOVA

We did not observe an interaction between the POMS (mood), PANAS (emotion), and ROS (restorative feeling) indices. This implies that there was no complex effect between the thinning of the forest environment and spending time in it. As for the psychological effects on mood, emotion, and the feeling of restoration, we did not observe any particular effect, either in terms of thinning or of forest stay.

A main effect of thinning was observed on $\operatorname{mood} \mathrm{C}(p<$ $0.01)$ and T-A $(p<0.1)$ (Table 4). Based on these results, it appears that thinning effectively influenced the $\mathrm{C}$ and $\mathrm{T}-\mathrm{A}$ indicators of mood. However, comparing the results for each indicator in the presence or absence of thinning in Table 8, the average POMS $\mathrm{C}$ score in the unthinned condition was 5.80, whereas that in the thinned condition was 3.40. After the experiment, the average POMS C score in the unthinned condition was 4.07 and that in the thinned condition was 2.00. Each of these values showed a significant difference. This indicates that the thinning did not decrease respondents' confusion, but their experimental experience in May helped to reduce their confusion because we carried out the second session in October within the same experimental area. Comparison of the mean T-A scores showed that they were significantly higher in the unthinned than the thinned condition $(p<0.05)$, but we did not observe any significant difference in the same comparison after the experiment. Therefore, we conclude that the experimental experience itself primarily influenced the respondents, rather than the influence of the thinned forest environment (Table 8).

Table 8 Results of multiple comparison tests between before and after thinning (setting) and pre-post (exposure to the forest) for Profile of Mood States (mood)

\begin{tabular}{|c|c|c|c|c|c|c|c|c|c|c|c|c|}
\hline & Unthinned & & & & & & Thinned & & & & & \\
\hline & Pre & & Post & & $p$ & & Pre & & Post & & $p$ & \\
\hline & Mean & S.D. & Mean & S.D. & & & Mean & S.D. & Mean & S.D. & & \\
\hline Tension-Anxiety & 4.20 & \pm 3.34 & 2.20 & \pm 2.91 & 0.006 & $* *$ & 3.07 & \pm 2.59 & 1.33 & \pm 1.45 & 0.017 & * \\
\hline Depression-Dejection & 1.47 & \pm 1.85 & 0.20 & \pm 0.56 & 0.002 & $* *$ & 1.33 & \pm 2.09 & 0.53 & \pm 0.62 & 0.043 & * \\
\hline Anger-Hostility & 0.40 & \pm 0.74 & 0.20 & \pm 0.77 & 0.383 & & 0.80 & \pm 1.22 & 0.27 & \pm 0.57 & 0.023 & $*$ \\
\hline Vigor & 5.07 & \pm 3.31 & 3.87 & \pm 3.54 & 0.160 & & 4.07 & \pm 3.30 & 3.00 & \pm 2.63 & 0.211 & \\
\hline Fatigue & 2.73 & \pm 2.22 & 0.93 & \pm 1.16 & 0.002 & $* *$ & 2.87 & \pm 2.87 & 1.80 & \pm 1.76 & 0.061 & $\#$ \\
\hline \multirow[t]{4}{*}{ Confusion } & 5.80 & \pm 2.24 & 4.07 & \pm 1.22 & 0.005 & $* *$ & 3.40 & \pm 5.65 & 2.00 & \pm 1.83 & 0.021 & $*$ \\
\hline & Pre & & & & & & Post & & & & & \\
\hline & Unthinned & & Thinned & & $p$ & & Unthinned & & Thinned & & $p$ & \\
\hline & Mean & S.D. & Mean & S.D. & & & Mean & S.D. & Mean & S.D. & & \\
\hline Tension-Anxiety & 4.20 & \pm 3.34 & 3.07 & \pm 2.59 & 0.043 & $*$ & 2.20 & \pm 2.91 & 1.33 & \pm 1.45 & 0.116 & \\
\hline Depression-Dejection & 1.47 & \pm 1.85 & 1.33 & \pm 2.09 & 0.561 & & 0.20 & \pm 0.56 & 0.53 & \pm 0.62 & 0.152 & \\
\hline Anger-Hostility & 0.40 & \pm 0.74 & 0.80 & \pm 1.22 & 0.021 & * & 0.20 & \pm 0.77 & 0.27 & \pm 0.57 & 0.687 & \\
\hline Vigor & 5.07 & \pm 3.31 & 4.07 & \pm 3.30 & 0.153 & & 3.87 & \pm 3.54 & 3.00 & \pm 2.63 & 0.214 & \\
\hline Fatigue & 2.73 & \pm 2.22 & 2.87 & \pm 2.87 & 0.698 & & 0.93 & \pm 1.16 & 1.80 & \pm 1.76 & 0.017 & $*$ \\
\hline Confusion & 5.80 & \pm 2.24 & 3.40 & \pm 5.65 & 0.000 & $* *$ & 4.07 & \pm 1.22 & 2.00 & \pm 1.83 & 0.000 & ** \\
\hline
\end{tabular}


Table 9 Results of two-way repeated measures ANOVA for Positive and Negative Affect Schedule (emotion)

\begin{tabular}{|c|c|c|c|c|c|c|c|c|c|}
\hline \multirow[t]{3}{*}{ PANAS } & \multicolumn{6}{|c|}{ Main effect } & \multirow{2}{*}{\multicolumn{3}{|c|}{$\frac{\text { Interaction }}{\text { Condition } \times \text { time }}$}} \\
\hline & \multicolumn{3}{|c|}{$\begin{array}{l}\text { Condition } \\
\text { Unthinned vs. thinned }\end{array}$} & \multicolumn{3}{|c|}{$\begin{array}{l}\text { Time } \\
\text { Pre vs. post }\end{array}$} & & & \\
\hline & $F$ & $p$ & $\eta^{2}$ & $\bar{F}$ & $p$ & $\eta^{2}$ & $F$ & $p$ & $\eta^{2}$ \\
\hline Negative & 0.63 & 0.434 & 0.001 & 0.77 & 0.387 & 0.001 & 0.12 & 0.731 & 0.001 \\
\hline Positive & 0.23 & 0.636 & 0.001 & 1.13 & 0.296 & 0.001 & 0.05 & 0.820 & 0.001 \\
\hline
\end{tabular}

two-way repeated measures ANOVA

We also confirmed the effect of the stay in the forest on mood (POMS; T-A, D, C) and restorative feeling (ROS). Further, there was a tendency for the forest to restore the respondents' exhausted mood (Table 7). The results were supported by the multiple comparison test results shown in Table 8; in the unthinned condition, the mean scores for T-A, D, F, C (POMS), and ROS showed a significant decrease after compared with before the experiment $(p<$ $0.01)$. In the thinned condition, a similar decrease in T-A, $\mathrm{D}, \mathrm{A}-\mathrm{H}$, and $\mathrm{C}$ mean scores was observed $(p<0.05)$ and a decreasing trend was observed in $\mathrm{F}(p<0.1)$. These results suggest that the respondents' mood improved and they felt restored by being in the forest environment during the experiment, irrespective of thinning. Importantly, this finding has not been reported in other research to date.

Regarding negative and positive emotion (PANAS), we did not observe any significant relationship in the interaction, the main effect, or in the multiple comparison tests, indicating that neither the thinning (unthinnedthinned) nor the forest stay (pre-post) had a direct effect on respondents' emotions. This is consistent with the results of previous studies, including that of Takayama et al. (2014b).

In this study, we conducted slight thinning to decrease the forest density by $16.6 \%$ and the total basal area by approximately $9.3 \%$ (Fig. 2 and Table 2). Appreciation of the forest environment did not differ significantly depending on whether the forest was thinned or unthinned. However, we observed a significant difference (or a trend) in some of the indicators (bright-dark, dry-wet, gentle lightingtoo bright, dull-refreshing, thin-thick), and as already discussed, it seems that this was because of the influence of the weather conditions during the experiments (Table 1).

In contrast, in the analysis of appreciation for the environment, the thin-thick indicator showed a trend: thinned (3.33) was evaluated as more deserted than unthinned (4.00). Moreover, because the physical changes due to the thinning and the appreciation corresponded, as a decrease in tree density and the total basal area of the thinned condition was recognized, we suggest the possibility that the thinned forest strengthened the impression of the forest environment being deserted.

For the restorative properties of the forest environment, there was no significant difference between the thinned and the unthinned environment for any of the indicators related to the restorative properties (being away, fascination, coherence, scope, and compatibility).

In general, the above results suggest that slight thinning, as executed in this study, does not affect appreciation of the environment and its restorative properties, except for a few indices. A few studies (e.g., Gifu Prefectural Research Institute for Forests 2004 and Oku 2007) have reported an increase in the psychological restorative effect and a general improvement in respondents' impressions with increased thinning. However, our result shows that this does not always apply to all factors. In other words, even with thinning of the somewhat managed forest, the relaxation effect (including the psychological restorative effect) will not

Table 10 Results of multiple comparison tests between before and after thinning (setting) and pre-post (exposure to the forest) for Positive and Negative Affect Scale (emotion)

\begin{tabular}{|c|c|c|c|c|c|c|c|c|c|c|}
\hline & Unthinned & & & & & Thinned & & & & \\
\hline & Pre & & Post & & $p$ & Pre & & Post & & $p$ \\
\hline & Mean & S.D. & Mean & S.D. & & Mean & S.D. & Mean & S.D. & \\
\hline Negative & 12.4 & \pm 4.82 & 11.0 & \pm 4.61 & 0.252 & 13.0 & \pm 5.21 & 12.5 & \pm 4.02 & 0.701 \\
\hline \multirow[t]{4}{*}{ Positive } & 23.5 & \pm 8.58 & 20.5 & \pm 9.49 & 0.174 & 23.9 & \pm 7.26 & 21.9 & \pm 7.43 & 0.336 \\
\hline & Pre & & & & & Post & & & & \\
\hline & Unthinned & & Thinned & & $p$ & Unthinned & & Thinned & & $p$ \\
\hline & Mean & S.D. & Mean & S.D. & & Mean & S.D. & Mean & S.D. & \\
\hline Negative & 12.4 & \pm 4.82 & 13.0 & \pm 5.21 & 0.658 & 11.0 & \pm 4.61 & 12.5 & \pm 4.02 & 0.263 \\
\hline Positive & 23.5 & \pm 8.58 & 23.9 & \pm 7.26 & 0.806 & 20.5 & \pm 9.49 & 21.9 & \pm 7.43 & 0.484 \\
\hline
\end{tabular}


Table 11 Results of two-way repeated measures ANOVA for Restorative Outcome Scale (subjective restorativeness)

\begin{tabular}{|c|c|c|c|c|c|c|c|c|c|c|}
\hline \multirow[t]{3}{*}{ ROS } & \multicolumn{7}{|c|}{ Main effect } & \multirow{2}{*}{\multicolumn{3}{|c|}{$\frac{\text { Interaction }}{\text { Condition } \times \text { time }}$}} \\
\hline & \multicolumn{3}{|c|}{$\begin{array}{l}\text { Condition } \\
\text { Unthinned vs. thinned } \\
\end{array}$} & \multicolumn{4}{|c|}{$\begin{array}{l}\text { Time } \\
\text { Pre vs. post }\end{array}$} & & & \\
\hline & $\bar{F}$ & $p$ & $\overline{\eta^{2}}$ & $\bar{F}$ & $p$ & & $\eta^{2}$ & $F$ & $p$ & $\eta^{2}$ \\
\hline & 0.05 & 0.829 & 0.001 & 5.94 & 0.021 & * & 0.111 & 1.35 & 0.255 & 0.002 \\
\hline
\end{tabular}

necessarily increase. This is an important finding that has not been reported in other papers on this topic (e.g., Ribe (1989); Ryan (2005); Ribe (2009); Schroeder and Green (1985); Gundersen and Frivoid (2011); Tyrväinen et al. (2014a)). Explanations for this observation include (1) the experimental plot, i.e., the experimental area of this study was a forest in which the density and undergrowth were already moderately managed before the experiment, and (2) the slight thinning enforced in this experiment did not reach the threshold value to make a difference in the appreciation of the forest environment and its restorative properties. To manage forests that have been only partially managed previously and have already gained a certain level of positive evaluation, it might be possible to carry out a continuous evaluation by repeated slight thinning with minimal effort.

Landscape appreciation and psychological restorative effect Considering the relationship between landscape appreciation (appreciation for and restorative properties of the environment) and its psychological restorative effect, there was a main effect (or trend) for the thinned compared with the unthinned forest (Table 8).

We do not discuss confusion further here, as it was considered to be influenced by the presence or absence of the experimental experience rather than the influence of thinning, as discussed previously. In contrast, improving the forest environment by thinning seemed to reduce the tension and anxiety of the respondents. However, its effect on appreciation for the forest environment was confirmed as a trend that was probably due to a difference in the thickness $(p<0.1)$ attribute and was actually rated higher in the thinned than the unthinned condition (Table 5).

In an attempt to aggregate the above discussion, at first sight it seems that thinning can improve respondents' appreciation of the forest environment, resulting in the reduction of tension and anxiety (main effect; $p<0.1$; Table 7). However, looking at the results of the multiple comparison tests (Table 8), although a significant difference was observed in the comparison of average scores regarding the presence or absence of thinning before the experiment, no such difference was observed after the experiment. Thus, the forest seems to reduce tension and anxiety more than confusion, regardless of thinning.

\section{Thinning and psychological restorative effect}

Following thinning, the physical indicators of management in the experimental area, such as tree density and total basal area, were reliably reduced. However, with respect to the psychological restorative effect, it was directly confirmed that there was almost no indicator influenced by thinning. In other words, there seemed to be no effect on any of the mood indices (T-A, D, A-H, $\mathrm{V}, \mathrm{F}, \mathrm{C}$ ), emotion (negative and positive affect), or restorative feeling, although a restorative effect seemed to be confirmed in some indicators after spending a certain period of time in the forest environment. Therefore, the difference in the psychological restorative effect may be a result of the precondition in which the original research plot was to some extent managed already as an artificial forest, or by the control condition in which weaker thinning was carried out in this study.

Based on the above discussion, and assuming the response system (stimulus $\rightarrow$ appreciation $\rightarrow$ response) according to Lazarus's stress model (Kosugi et al. 2002), we could suggest that the change in the external environment influenced the environmental appreciation of "deserted-dense" (Table 5). Finally, the result of this appraisal (greater appreciation for deserted) did not have a restorative psychological effect. In other words,

Table 12 Results of multiple comparison tests between before and after thinning (setting) and pre-post (exposure to the forest) for Restorative Outcome Scale (subjective restorativeness)

\begin{tabular}{|c|c|c|c|c|c|c|c|c|c|c|}
\hline \multicolumn{6}{|l|}{ Unthinned } & \multicolumn{5}{|l|}{ Thinned } \\
\hline Pre & & Post & & $p$ & & Pre & & Post & & $p$ \\
\hline Mean & S.D. & Mean & S.D. & & & Mean & S.D. & Mean & S.D. & \\
\hline 25.73 & \pm 3.22 & 29.53 & \pm 4.37 & 0.001 & $* *$ & 26.60 & \pm 3.64 & 28.27 & \pm 4.50 & 0.110 \\
\hline Pre & & & & & & Post & & & & \\
\hline Unthinned & & Thinned & & $p$ & & Unthinned & & Thinned & & $p$ \\
\hline Mean & S.D. & Mean & S.D. & & & Mean & S.D. & Mean & S.D. & \\
\hline 25.73 & \pm 3.22 & 26.60 & \pm 3.64 & 0.353 & & 29.53 & \pm 4.37 & 28.27 & \pm 4.50 & 0.178 \\
\hline
\end{tabular}


conducting weaker thinning of a moderately managed forest for recreational use, as in this study, could enhance the appreciation of the forest by decreasing the tree density; nevertheless, the results also imply that there may be no psychological restorative effect of staying in a forest.

\section{Conclusions}

The results of this study indicate that when performing thinning in a forest located in a summer resort spot near the city used primarily for forest recreation and forest bathing, approximately half the amount (15 to $20 \%$ ) of standard thinning (30 to $40 \%$ ) in forestry regions was sufficient to accomplish the management of the forest without changing the user's appreciation and the restorative effect.

In general, managing the density of trees, the design of paths, installation of facilities such as billboards and arbors, and management plans that secure all of these aspects are potential challenges to enhancing the physical and mental restorative effect of the forest. However, because the forest environment itself is composed of a variety of flora and fauna, and facilities age quickly, it is essential to consider the cost of constructing these facilities (which must be new) and maintaining the diversity of animals and plants, which is the infrastructure of the forest. For example, if we need to implement a forest management method that involves reducing the tree density by at least $16-17 \%$ and the total basal area by $9-10 \%$, the removal of primarily small-diameter and suppressed trees will achieve this while maintaining the forest's mental and physical restorative effects and, at the same time, reducing management costs. Thus, we can propose to develop a rational and sustainable management method that protects large-diameter trees to ensure future management funds.

\section{Summary}

The following three points summarize the main findings of the study:

- The evaluation of the restorative effects of the forest environment did not change after the slight thinning of the urban forest that had been maintained to some extent, except for some impression evaluations.

- The weak thinning of the suburban forest had less of an effect on impression evaluations than did the effect of the weather conditions during the experimental period.

- The psychological restorative effects of the lightly maintained suburban forest were not always improved by weak thinning.

\section{Limitations}

Because the present study involved conducting two experiments in different forest conditions (thinned and unthinned) with the same respondents, we selected 15 people who could participate in both conditions. Similar to other psychological experiments conducted on-site (e.g., Oishi et al. 2003; Park et al. 2009; Tsunetsugu et al. 2010; Park et al. 2010; Horiuchi et al. 2014), this study could be considered as an empirical case study conducted with a nofunction condition because the respondents were the same in both experiments. However, the number of respondents used to obtain the results was relatively small, and the properties of the forest environment varied depending on the climatic zones, biota, and management conditions of each region. Therefore, we must be sufficiently cautious in generalizing the knowledge gained through this experiment. We strived to carry out the two experiments in May and October under similar conditions except for the thinning; nevertheless, strict control of some conditions, such as the weather and season-specific flora and fauna, was not possible. Moreover, the experiments were carried out while the respondents were relaxing on a chair in the forest, but we must acknowledge that other activities, such as taking a leisurely stroll, are also common in a forest. Thus, we need to perform further experiments to understand the effects of thinning while performing other activities such as strolling. In addition, the respondents who participated in this research were graduate students or faculty members in forest science, which means there is a possibility that the results of this experiment might not apply to general forest users. Lastly, the difficulty of controlling weather conditions is a critical problem for on-site experiments. For strict control, it would be necessary to use a climate-controlled room with pre-determined weather conditions.

\section{Future research}

To generalize the results of this study, additional research is necessary, including experiments and laboratory tests using videos and photos as well as a greater range of respondents. Furthermore, we found that thinning improved the impression of the forest environment, as measured by an improvement in some indicators of mood. This aspect can be understood through theories such as Appleton's (1996) prospect-refuge theory, which posits that one's fear of the natural environment can be mitigated. Thus, to make forests comfortable spaces for recreation and mental restorative purposes, it is important for forest managers to gather additional information concerning the relationship between the prospect of a forest and a sense of fear, insecurity, or nervousness of the forest environment; however, this type of empirical research is not yet common.

In this study, the psychological restorative effect of forests was not increased by thinning. However, as Appleton (1996) states in his "prospect-refuge theory," a good prospect environment in which one can observe while remaining unseen by others is a necessary condition for peace of mind; hence, higher psychological and physical 
restorative effects may be expected when dense forests are thinned more than they were in this study. It is important to conduct additional experiments to assess users of the forest and its restorative effects. For example, an additional experiment could compare two forest environments of the same type, one unmanaged and natural and the other a maintained forest used for recreation or forest bathing.

\section{Abbreviations}

PANAS: Positive and Negative Affect Schedule; POMS: Profile of Mood States: PRS: Perceived Restorativeness Scale; ROS: Restorative Outcome Scale; SD: Semantic Differential

\section{Acknowledgements}

The ethical committee of the Mt. Fuji Research Institute approved all procedures applied in the present study in accordance with the guidelines of the Declaration of Helsinki. Before the experiment, the respondents had sufficient informed consent and agreed to participate in the experiments. We thank all of the respondents who gave their time and effort to this study. We gratefully appreciate the financial support (awarded to M.H.) of the Yamanashi Institute of Environmental Sciences and Japan Society for the Promotion of Science (No. 26400268 to M.H.) and the academic research grant (awarded to H.S. and A.K) of the Yamaguchi Scholarship Foundation. We express our gratitude to the following for their help in organizing the experiments and giving us useful suggestions through their discussion: Kazutaka Murase, Norio Nishiyama, Junko Endo, Yuko Asano, Susumu Goto, and Junko Saito.

\section{Funding}

Not applicable

\section{Authors' contributions}

$\mathrm{NT}, \mathrm{MH}, \mathrm{HS}$, and $\mathrm{AF}$ contributed to the conception and design of the study, performed the experiments, analyzed the data, and prepared the figures and tables. NT, HS, and AF interpreted the results of the experiment; $\mathrm{MH}$ and $\mathrm{HS}$ obtained the grants for the study. NT wrote the first draft and all authors revised the manuscript. All authors approved the final version of the manuscript.

\section{Competing interests}

The authors declare that they have no competing interests.

\section{Publisher's Note}

Springer Nature remains neutral with regard to jurisdictional claims in published maps and institutional affiliations.

\section{Author details}

${ }^{1}$ Division of Forest Management, Forestry and Forest Products Research Institute in Japan, 1 Matsuno-sato, Tsukuba City, Ibaraki 305-8687, Japan. ${ }^{2}$ Fuji Iyashinomoroi Woodland Study Center, The University of Tokyo, Yamanaka 341-2, Yamanakako Village, Minami-tsuru, Yamanashi 401-0501, Japan. ${ }^{3}$ Division of Human Environmental Science, Mt. Fuji Research Institute, 5597-1 Kami-Yoshida, Fuji-Yoshida City, Yamanashi 403-0005, Japan.

Received: 30 May 2016 Accepted: 22 May 2017

Published online: 28 June 2017

\section{References}

Appleton J (1996) The experience of landscape. Wiley, New York

Brunson MW, Reiter DK (1996) Effects of Ecological Information on Judgments about Scenic Impacts of Timber Harvest. J Environ Manag 46:31-41. doi:10. 1006/jema.1996.0004

Brunson MW, Shelby B (1992) Assessing recreational and scenic quality. J For 90:37-41

Buhyoff GJ, Leuschner WA (1978) Estimating Psychological Disutility from Damaged Forest Stands. For Sci 24:424-432

Daniel TC (2006) Public preferences for future conditions in disturbed and undisturbed northern forest sites. Public Wild Fire Manag Soc Sci Find Manag 53-62. https://www.nrs.ff.fed.us/pubs/gtr/gtr_nrs1.pdf\#page=63
Deng S, Yan J, Guan Q, Katoh M (2012) Short-term effects of thinning intensity on scenic beauty values of different stands. J For Res 18:209-219. doi:10. 1007/s10310-012-0342-5

Edwards D, Jay M, Jensen FS et al (2012) Public preferences for structural attributes of forests: Towards a pan-European perspective. Forest Policy Econ 19:12-19. doi:10.1016/j.forpol.2011.07.006

Food and Agriculture Organization (2007) Food and Agriculture Organization of the United Nations State of the World's Forest., http://www.fao.org/docrep/ 009/a0773e/a0773e00.htm. Accessed on 6 June 2014

Forestry Agency of Japan (2016) Annual Report on Trends in Forests and Forestry (in Japanese) Fiscal Year 2015

Fujisawa M, Takayama N (2014) Verification of Restorative Effect in Off-site Forest Bathing by ROS Japanese Edition. Pap Environ Inf Sci (in Japanese) 28:316-366

Fujisawa M, Takayama N, Morikawa T (2012) Study on Physiological Response and Subjective Appraisal Brought visually by a Light Environment of a Forest. Pap Environ Inf Sci (in Japanese) 26:103-106

Gifu Prefectural Research Institute for Forests (2004) Methods of Thinking and Management of the forest Landscape (in Japanese). Gifu Prefectural Research Institute for Forests,Gifu

Gobster PH (1999) An ecological esthetic for forest landscape management. Landsc J 18:54-64

Guan Q, Deng S, Yan J (2010) Effects of Thinning Intensity on the SBE in Different Types Stand

Gundersen V, Frivoid LH (2011) Naturally dead and downed wood in Norwegian boreal forests: public preferences and the effect of information. Scand J For Res 26:110-119

Haluza D, Schönbauer R, Cervinka R (2014) Green perspectives for public health: a narrative review on the physiological effects of experiencing outdoor nature. Int J Environ Res Public Health 11:5445-61. doi:10.3390/ijerph110505445

Hartig T (2005) personal communication, January

Hartig T, Florian GK, and Peter AB. (1997a) Further development of a measure of perceived environmental restorativeness. Working Paper (5), Institutet för bostadsforskning, Gävle

Hartig T, Korpela K, Evans GW, Gärling T (1997b) A measure of restorative quality in environments. Scand Hous Plan Res 14:175-194

Hartig T, Lindblom K, Ovefelt K (1998) The home and near-home area offer restoration opportunities differentiated by gender. Scand Hous Plan Res 15: 283-296. doi:10.1080/02815739808730463

Hartig T, Evans GW, Jamner LD et al (2003) Tracking restoration in natural and urban field settings. J Environ Psychol 23:109-123

Herzog TR, Chernik KK (2000) Tranquility and danger in urban and natural setting. J Environ Psychol 20:29-39

Horiuchi M, Endo J, Takayama N et al (2014) Impact of Viewing vs. Not Viewing a Real Forest on Physiological and Psychological Responses in the Same Setting. Int J Environ Res Public Health 11:10883-10901. doi:10.3390/ ijerph111010883

Iwashita T (1983) Guide of measurement - understanding and enforcement of the image by the SD method (in Japanese). Kawashima shoten, Tokyo

Kaplan R, Kaplan S (1989) The Experience of Nature: A Psychological Perspective, 1st edn. Cambridge University Press, New York

Kaplan S, Bardwell LWW, Slakter DB, Kaplan S (1993) The museum as a restorative environment. Environ Behav 25:725-742

Kobayashi H, Song C, lkei H et al (2015) Analysis of Individual Variations in Autonomic Responses to Urban and Forest Environments. Evid Based Complement Alternat Med 2015:671094. doi:10.1155/2015/671094

Korpela K, Hartig T (1996) Restorative qualities of favorite places. J Environ Psychol 16:221-233. doi:10.1006/jevp.1996.0018

Korpela KM, Ylén M, Tyrväinen L, Silvennoinen H (2008) Determinants of restorative experiences in everyday favorite places. Health Place 14:636-652

Korpela KM, Ylén M, Tyrväinen L, Silvennoinen H (2010) Favorite green, waterside and urban environments, restorative experiences and perceived health in Finland. Health Promot Int 25:200-209

Kosugi S, Shimazu A, Tanaka K et al (2002) Stress Psychology -A process and coping of the individual difference (in Japanese). Kawashima shoten, Tokyo

Kunisaki T, Imada M (1996) Changes in visual penetration in a plantation after thinning. Japanese J For Plan (in Japanese):26:51-58

Laumann K, Gärling T, Stormark KM (2003) Selective attention and heart rate responses to natural and urban environments. J Environ Psychol 23:125-134

Li Q, Morimoto K, Nakadai A et al (2007) Forest bathing enhances human natural killer activity and expression of anti-cancer proteins. Int J Immunopathol Pharmacol 20:1-8 
Li Q, Morimoto K, Kobayashi M et al (2008a) A forest bathing trip increases human natural killer activity and expression of anti-cancer proteins in female subjects. J Biol Regul Homeost Agents 22:45-55

Li Q, Morimoto K, Kobayashi M et al (2008b) Visiting a forest, but not a city, increases human natural killer activity and expression of anti-cancer proteins. Int J Immunopathol Pharmacol 21:117-127

McNair DM, Lorr M, Maurice $L$ (1964) An analysis of mood in neurotics. J Abnorm Soc Psychol 69:620-627

Morita E, Nagano J, Fukuda S et al (2009) Relationship between forest walking (shinrin-yoku) frequency and self-rated health status: cross-sectional study of healthy Japanese. Jpn J Biometeorol (in Japanese) 46:99-107

Ochiai H, Ikei H, Song C et al (2015a) Physiological and Psychological Effects of Forest Therapy Program on Middle-Aged Females. Int J Environ Res Public Health 12:2532-2542. doi:10.3390/ijerph120302532

Ochiai H, Ikei H, Song C et al (2015b) Physiological and Psychological Effects of Forest Therapy on Middle-Aged Males with High-Normal Blood Pressure. Int J Environ Res Public Health 12:2532-2542. doi:10.3390/ijerph120302532

Ohira H, Takagi S, Masui K et al (1999) Effects on shinrin-yoku (forest-air bathing and walking) on mental and physical health. Bull Tokai Women Univ (in Japanese) 19:217-232

Oishi Y, Hiyane A, Taguch H, Murai H (1994) Analysis for psychology in a forest environment: Semantic differential method in the experimental forest of recreational function. Japanese J For Plan (in Japanese):23:33-44

Oishi Y, Kanehama S, Hiyane A, Taguchi H (2003) Comparison of Forest Image and Wood: Psychological Examination in a Forest Environment Using Profile of Wood States and Semantic Differential Method. J Jpn For Soc (in Japanese) 85:70-77

Oku H (2007) How does make a forest landscape? In: Oku H, Kagawa T, Tanaka N (eds) Guide for making with attractive forest Landscape (in Japanese), 1st edn. National forestry improvement Promotion Association, Tokyo, p 275

Park BJ, Tsunetsugu Y, Kasetani T et al (2009) Physiological effects of forest recreation in a young conifer forest in Hinokage town, Japan. Silva Fenn 43:291-301

Park BJ, Tsunetsugu Y, Kasetani T et al (2010) The physiological effects of Shinrinyoku (taking in the forest atmosphere or forest bathing): evidence from field experiments in 24 forests across Japan. Environ Health Prev Med 15:18-26. doi:10.1007/s12199-009-0086-9

Park BJ, Furuya K, Kasetani T et al (2011) Relationship between psychological responses and physical environments in forest settings. Landsc Urban Plan 102:24-32. doi:10.1016/j.landurbplan.2011.03.005

Ribe RG (1989) The esthetics of forestry: What has empirical preference research taught us? Environ Manage 13:55-74. doi:10.1007/BF01867587

Ribe RG (2005) Comparing Changes in Scenic Beauty Produced by Green-Tree Retention Harvests, Thinnings and Clearcuts: Evidence From Three Pacific Northwest Experiments. In: Maguire and others (eds.) Balancing Ecosystem Values: Innovative Experiments for Sustainable Forestry. USDA Forest Service, General Technical Report PNW-635. Portland, OR. 137-146.

Ribe RG (2006) Perceptions of forestry alternatives in the US Pacific Northwest: Information effects and acceptability distribution analysis. J Environ Psychol 26:100-115. doi:10.1016/j.jenvp.2006.05.004

Ribe RG (2009) In-stand scenic beauty of variable retention harvests and mature forests in the U.S. Pacific Northwest: The effects of basal area, density, retention pattern and down wood. J Environ Manage 91:245-260. doi:10. 1016/j.jenvman.2009.08.014

Ryan RM (2005) Social science to improve fuels management: A synthesis of research on esthetics and fuels management. Gen Tech Rep NC, vol 261. USDA, Forest, St Paul

Ryan RM, Frederick CM (1997) On energy, personality and health: Subjective vitality as a dynamic reflection of well-being. J Pers 65:529-565

Sato A, Yasuda A (2001) Development of the Japanese version of Positive and Negative Affect Schedule (PANAS) scales. J Character Psychol (in Japanese) 9: 138-139

Schroeder HW, Green TL (1985) Public preference for tree density in municipal parks. J Arboric 11:272-277

Shibata S, Hata T, Miwa Y (2008) Perceived Restorativeness Scale (PRS) Translation and Validation of a Japanese Version of the Perceived Restorativeness Scale (PRS). MERA J (in Japanese) 11:1-10

Spielberger CD, Gorsuch RL, Lushene RE (1970) STAI manual for the State-trait anxiety inventory "self-evaluation questionnaire.". Consulting Psychologist Press, Sunnyvale

Spielberger CD, Gorsuch RL, Lushene R et al (1983) Manual for the State-Trait Anxiety Inventory (Form Y) ("Self-Evaluation Questionnaire")., pp 1-37
Staats H, Kieviet A, Harting T, Hartig T (2003) Where to recover from attentional fatigue: expectancy-value analysis of environmental preference. J Environ Psychol 23:147-157

Takahashi N, Kanno T, Nobori Y (2006) Effects of mixture type and the ratio of broad-leaved trees on preferences in evaluations of landscapes of mixed forests with coniferous and broad-leaved trees. Jpn J For Plan (in Japanese) 40:191-201

Takanashi T (2011) A study on Application of Forest Landscape Management Guidelines to the Maintenance of Non-Tending Artificial Forests of SATOYAMA. Bulletion JSSD 58:78-86

Takayama N, Kagawa T (2013) Study on a Function of the Forest Environment as the Restorative Environment Using the Attention Restoration Theory. J Jpn Inst Landsc Archit (in Japanese) 76:539-542. doi:10.5632/jila.76.539

Takayama N, Kawaguchi T, Kasetani T et al (2009) The Relation between the Measured Environmental Factors and the Evaluation Factors Extracted from Onsite Forest Environment. J Jpn Inst Landsc Archit (in Japanese) 72:669-672

Takayama N, Fujisawa M, Aramaki M, Mmorikawa T (2012) Influence of Subjective Appraisal and Personality and Other Traits to Psychological Stress Reduction Effect Caused by the Sunshine Filtering Through Foliage in the Forest Picture. J Jpn Inst Landsc Archit (in Japanese) 75:565-570. doi:10.5632/jila.75.565

Takayama N, Fujiwara A, Saito H et al (2014a) Cognitive traits derived from the difference between scenery viewing and covering in on-site forest environment. Kanto J For Res (in Japanese) 65:157-158

Takayama N, Korpela K, Lee J et al (2014b) Emotional, restorative and vitalizing effects of forest and urban environments at four sites in Japan. Int J Environ Res Public Health 11:7207-7230. doi:10.3390/ijerph110707207

Tsunetsugu Y, Park BJ, Miyazaki Y (2010) Trends in research related to "Shinrinyoku" (taking in the forest atmosphere or forest bathing) in Japan. Environ Health Prev Med 15:27-37

Tsunetsugu Y, Lee J, Park BJ et al (2013) Physiological and psychological effects of viewing urban forest landscapes assessed by multiple measurements. Landsc Urban Plan 113:90-93. doi:10.1016/j.landurbplan.2013.01.014

Tyrväinen L, Uusitalo M, Silvennoinen H, Hasu E (2014a) Towards sustainable growth in nature-based tourism destinations: Clients' views of land use options in Finnish Lapland. Landsc Urban Plan 122:1-15. doi:10.1016/j. landurbplan.2013.10.003

Tyrväinen L, Ojala A, Korpela K et al (2014b) The influence of urban green environments on stress relief measures: A field experiment. J Environ Psychol 38:1-9. doi:10.1016/j.jenvp.2013.12.005

Ulrich RS (1984) View through a window may influence recovery from surgery. Science 224:420-421

Velarde MD, Fry G, Tveit M (2007) Health effects of viewing landscape-Landscape types in environmental psychology. Urban For Urban Green 6:199-211

Watson D, Clark LA, Carey G (1988a) Positive and negative affectivity and their relation to anxiety and depressive disorders. J Abnorm Psychol 97:346-353

Watson D, Clark LA, Tellegen A (1988b) Development and validation of brief measures of positive and negative affect: The PANAS Scales. J Pers Soc Psychol 47:1063-1070. doi:10.1037/0022-3514.54.6.1063

Yokoyama K, Araki S, Kawakami N, Takeshita T (1990) Production of the Japanese edition of profile of mood states (POMS): Assessment of reliability and validity. Jpn J Public Health (in Japanese) 37:913-918

\section{Submit your manuscript to a SpringerOpen ${ }^{\odot}$ journal and benefit from:}

- Convenient online submission

- Rigorous peer review

- Open access: articles freely available online

- High visibility within the field

- Retaining the copyright to your article

Submit your next manuscript at $>$ springeropen.com 